\title{
Educational videos - tell me what you want, what you really, really want
}

\section{Paul Rice}

University of Northampton, UK

\section{Robert Farmer}

University of Northampton, UK

\begin{abstract}
Given the current popularity of educational videos, and given the time, effort and expense academics and institutions are investing to provide educational videos to students, it was thought worthwhile to evaluate whether students at the University of Northampton (UoN) actually want and use these resources. Moreover, if it was found they do use educational videos, investigation was required to determine if they are in a format that students want. The study was carried out in two distinct stages. The first stage was a questionnaire which was followed by a focus group. It was found that students at Northampton do overwhelmingly use educational videos. Furthermore, the research found that students prefer videos to any other resource and that videos can increase motivation. Additionally, high-risk production strategies, such as seeing the presenter on screen, and the use of animation, humour and quizzes were identified, and it was found that the use of music in an educational video was considered a negative component of a video. The optimum length of the video is less clear, however, it is recommended they are kept to less than 10 minutes (although this is dependent upon the level of study of the student). The key recommendation when producing videos is to ensure they have been designed taking cognitive research into account. The key strength of a well-designed educational video, it is concluded, is to give the students something additional they cannot find in another resource, in a way which encourages effective learning.
\end{abstract}

Keywords: educational video, multimedia principles, student experience 


\section{Introduction}

In my role as an academic tutor for maths at the Centre for Achievement and Performance (the learning development centre at the UoN), I support any student on any course with any mathematics or statistics related query. It is well documented (by, for example, MacGillivray and Croft, 2011) that the provision of learning development centres increase students' motivation, confidence, grades, and, ultimately, retention. However, due to the very small size of our mathematics and statistics team (i.e. one full-time member of staff), it is not possible that face-to-face support can be given to all students. Therefore it is necessary to complement and augment the face-to-face interactions with an online offering which would still retain important human features, such as being motivational, building confidence, empathising and, importantly, having a sense of humour. To meet these objectives, educational videos were created, as these are generally considered to be the most personal type of educational resource (Moreno and Ortegano-Layne, 2008). Therefore we wanted to identify from a student's perspective which aspects of educational videos are engaging, increase confidence, promote motivation, and enhance knowledge.

The purpose of this paper is to disseminate the results of research undertaken on what students at the UoN actually want from, and think about, educational videos. Essentially, the primary goal was to determine what makes educational videos appealing to students within the context of supporting their learning and academic development. Specific questions that we wanted to answer included:

- Do students at Northampton engage with educational videos?

- Do educational videos impact on the learning and confidence of students?

- What are the key features (e.g. content, presentation, humour, music, production quality etc.) of 'good' educational videos?

Examining what made videos appealing to students (and investigating what disengaged students) provided an insight for us to improve our current offering, and gave us clear ideas about what should and should not be included in the production of future mathematics, statistics and SPSS videos. 


\section{Literature review}

A review of the literature showed that there are four kinds of educational videos namely: lecture based; enhanced; supplementary; and worked examples. Lecture based videos are a complete recording of a lecture. Enhanced videos are essentially PowerPoint presentations with an audio narrative. A supplementary video provides additional background information to broaden and deepen a student's understanding. Finally, a worked example video provides a visual explanation of a specific area demonstrating a sequential process (Kay, 2012). Regarding teaching approaches, educational videos can be further classified, as per Kay and Kletskin (2012), as either receptive viewing or problem-based. Receptive viewing refers to a passive approach, where the student views a video without any direct involvement, whereas problem-based videos will require the student to participate in some way. This research investigates worked examples of educational videos, however, with the increasing development of educational videos being made available to students, this section will adopt a general overview of educational videos.

Millions of pounds are being invested in higher education to enhance the quality of resources (Nikoi et al., 2011). According to Hilton III et al., (2013), using educational videos will save money in the long term as they may encourage the reduction in price of textbooks in order to compete. Bliss et al. (2013) agrees that educational resources are beneficial in terms of cost, but then goes beyond cost in isolation and examines the impact of educational resources using the 'COUP framework' (Cost, Outcome, Use, Perceptions) and advocates the use of educational videos. However, critics question if the time and expense incurred to produce educational videos is money well spent (Littlejohn et al., 2008). It takes time for academics to learn the necessary skills to produce educational videos, but it could be argued some are not fit for purpose from a students' perspective.

As with any other teaching material, videos need to be subject to a continuous quality assurance process (Williams et al., 2011). Therefore content (accuracy and relevance), pedagogy (learning outcome, design and assessment), accessibility and fitness for purpose all need to be monitored. However, it has been argued that although educational videos provide content, they do not necessarily encourage for deep understanding, context, and environmental components that are essential for effective learning (Bates, 2011). Furthermore, as argued by Panke and Seufert (2013, p.116), 'If we focus solely on 
access, we cannot differentiate between processes of mere information foraging and deep sense making activities'. Therefore caution is required so as not to confuse download and registration rates as a measure of quality of materials or of the amount of actual learning taking place. In a comprehensive review of the literature (53 peer reviewed articles), Kay (2012, p.825) found 'in terms of affective attitudes toward video podcasts, the current literature review revealed only positive responses'. However, he did go on to state 'with respect to cognitive attitudes several concerns were noted'. One such concern that has been raised regarding educational videos are that they are sometimes viewed in a sequential, linear and passive manner, which prevents long term learning (Ibrahim et al., 2014; Hegarty et al., 2003). One possible explanation for this point of view is that successful learning from videos requires a high level of cognitive processing (Ibrahim et al., 2012). Furthermore, for effective learning to take place, Mayer (2009) argues grounding in cognitive theory and production qualities are necessary elements of an educational video. However, due to the rapid proliferation of educational videos, (Cooper and Higgins, 2014; Kannan and Baker, 2014) this will not always be the case. Many students turn to YouTube for support to fill gaps in their learning. Worldwide, YouTube claim to have over 1 billion users. Every day people watch hundreds of millions of hours on YouTube and every day over 400,000 hours of video are uploaded (YouTube, 2015). In addition, many educational institutions produce in-house video content, and organisations offering open learning systems, such as Coursera, TED, and Khan Academy, are growing in popularity. An additional challenge found for not using educational videos is associated with technical issues such as file size, download speed, and students not having a mobile device (Kay, 2012). However, with advances in technology and greater availability of devices, it is expected these issues will diminish and educational videos will be used even more in the coming years (Vieira et al., 2014).

Clark and Mayer (2011) state the aim of effective learning is to engage the student in active cognitive processing. Thus learning works as people are active sense makers and not passive recipients of information. This knowledge construction view is based on three principles of Mayer's (2009) Cognitive Theory of Multimedia Learning (CTML) that explains how students learn from multimedia resources. Those principles are; dual channels (people have different channels for processing audio and visual content); limited capacity (people can only process limited information at any given time); and active processing (organise information and integrate with what they already know). Therefore there are three important stages for the learner. First, they must select words and images. Second, 
they need to organise the words and images, (this is done in working memory). Finally, the learner needs to integrate incoming material with existing knowledge (from long term memory) in order to construct a new meaning. The difficulty facing learners is to carry out these processes within the limitations of working memory. Cognitive load theory (Paas et al., 2010) suggests the working memory can only hold and process a finite amount of information at any one time, and learners can only process information if it is supplied in such a way not to overload the working memory. There are three types of cognitive load which are especially applicable to educational videos. They are to reduce extraneous cognitive load (information not related to objective), manage essential cognitive load (reduce complexity of essential material) and increase germane load (provide deeper learning by including relevant interactions).

Designing videos for effective learning should therefore take account of these conclusions from cognitive theory to combat the arguments made against educational videos. Although there is not a one model fits all style of video, there are a number of simple features that designers of educational videos can implement to support learners, namely: cues to highlight essential information (Morrain and Swarts, 2011; Clark and Mayer, 2011); user paced segments (Kay and Kletskin, 2012; Clark and Mayer, 2011); conversational style (Kay and Kletskin, 2012; Clark and Mayer, 2011); corresponding words and pictures presented simultaneously (Mayer, 2009; Clark and Mayer, 2011), and the exclusion of extraneous information (Mayer, 2009; Clark and Mayer, 2011). If these are implemented in an educational video, it is argued that learners will be more easily able to process key information, resulting in better understanding and learning (Wiley, 2010).

Although there is plenty of literature about the design of educational videos, there is very little research about what students want from an educational video. The Synthesis Report (McGill et al., 2013, online) claims that 'most subject strand projects expressed frustration that they did not have the time or funding to research what learners actually want from open educational materials'. Furthermore, in his comprehensive review of the literature, Kay (2012) found no research that had been carried out on the components of an educational video. Therefore it is imperative to gain feedback from students to ensure that they are appropriate, and are designed to encourage a student-centred approach and to enhance learning. 


\section{Methodology}

The population of the study was defined as all students at the University of Northampton. A sequential, mixed-method design, as outlined by Creswell (2009), consisting of two distinct stages was implemented. This initially provided exploratory quantitative data which was followed up with a deeper analysis using qualitative data. Quantitative data generated numerical data which was used to make generalisable conclusions, whereas the qualitative data was used to give in-depth understanding of individuals' perceptions. Hence the research benefitted from both quantitative and qualitative analysis, providing some degree of both objectivity and subjectivity.

The first stage of the research was to compile a questionnaire which was distributed using a probability sampling method to reduce bias by ensuring that everyone in the population had an equal chance of being included in the sample (see, for example, McMillan and Weyers, 2007). Due to the fact no previous studies of this type have been undertaken, no formal sample size calculations were made, however, the convenience sample, which was taken over a four week period prior to the Easter vacation, aimed to capture over 80 responses. The questionnaire link was available via the home page of the students' virtual learning environment (known as NILE, Northampton's Integrated Learning Environment), thus all students had an equal chance of responding. The questionnaire consisted of a combination of five point likert rating scale questions ( 1 being very important and 5 being not very important), and single response multiple choice questions to capture demographical data. Students were asked questions on how often they watch educational videos, the purpose of them watching the video, the impact of the video, how important individual components of a video are, and the optimum length of the video. The online survey was administered using Bristol Online Surveys (BOS) and data was exported directly into a statistical package (SPSS v.20) for analysis. The questionnaire was analysed first, with the goal of testing hypotheses for significant differences. The results were then used to inform the direction of the focus groups.

Data was captured from 89 students, however, after cleaning the data from the online survey, there were 87 responses remaining (males $=35$, females $=52$ ). For a breakdown by gender and year of study, see Table 1 below. A chi-square test was applied to the data (six students had not specified year or gender), which showed there were no significant differences between gender and year of study $\left(X^{2}=2.24, d f=3, p>0.05\right)$, and therefore due 
to the independence, any subsequent differences found for gender or year of study would be attributed correctly.

\begin{tabular}{|l|l|l|l|l|l|}
\hline Year & 1st & 2nd & 3rd & PostGrad & Total \\
\hline Male & 10 & 15 & 7 & 1 & 33 \\
\hline Female & 8 & 12 & 22 & 6 & 48 \\
\hline Total & 18 & 27 & 29 & 7 & 81 \\
\hline
\end{tabular}

Table 1. Gender of respondents broken down by level of study.

Respondents who completed stage one were asked to participate in stage two. In this second stage a qualitative approach was used to collect text data through a focus group. This group was to help explain why variables tested in the first phase may or may not be significant. Semi-structured interview questions were used to develop a conversational approach amongst the group and the interviewer. During the focus groups students were asked to give their opinions on four educational videos. Each of the four videos was regarding referencing and all four followed a worked example format. The focus group was recorded and transcribed verbatim. Initial codes were applied to the transcript, which were followed by more focused coding (as discussed by Lofland and Lofland, 1995). This approach allowed for themes to be developed which examined the connections between different codes.

The rationale for a deductive followed by inductive approach is that the quantitative data and results provided a general overview, while the qualitative aspect provided a refined and detailed analysis (see Johnson and Christian, 2008). Each stage was given equal priority and the results of both stages are integrated in the discussion section.

All the students who completed the questionnaire were invited to attend a focus group. Out of the 87 completed questionnaires, seven students volunteered to take part. No incentive was provided to complete the questionnaire or attend the focus group. See Table 2 for breakdown of gender and level of study. 


\begin{tabular}{|l|l|l|l|l|l|}
\hline Year & 1st & 2nd & 3rd & PostGrad & Total \\
\hline Male & 1 & 0 & 2 & 0 & 3 \\
\hline Female & 0 & 1 & 3 & 0 & 4 \\
\hline Total & 1 & 1 & 5 & 0 & 7 \\
\hline
\end{tabular}

Table 2. Breakdown of gender by level of study for focus groups.

\section{Limitations}

Because of the convenience sampling used in the quantitative phase of the study, it is not possible to say with confidence whether the sample is representative of the population. Moreover, due to the nature of the qualitative stage, small numbers in the focus group did not represent all areas of the target population. For example, international and postgraduate students were not adequately represented. Furthermore, the data obtained in the second phase of the study may be subject to different interpretations by different readers, and because of the interpretative nature of the second phase the investigator may have also introduced their bias into the analysis of the findings. Finally, the study relies upon students' personal perceptions, which might not match reality, and thus the study does not measure actual impact of educational videos on learning outcomes

\section{Results}

\section{Quantitative}

The initial objective of the project was to find out whether students are actually using open educational videos and how these compare with other resources. It was found that $94.3 \%$ (82 out of 87 ) students do watch educational videos. Furthermore, out of those 82 students who do watch educational videos, $96.8 \%$ of those watch educational videos which are directly related to their course. 


\begin{tabular}{|l|cc|cc|cc|}
\hline & \multicolumn{9}{|l|}{$\mathbf{1}=$ positive, $5=$ negative $)$} \\
\hline & \multicolumn{2}{|c|}{ Importance } & \multicolumn{2}{l|}{ confidence } & knowledge \\
\hline Resource & Mean & Std Dev & Mean & Std Dev & Mean & Std Dev \\
\hline Podcast & 2.62 & 1.22 & 2.41 & 1.04 & 2.28 & 1.03 \\
\hline PowerPoint & 1.74 & 0.89 & 1.82 & 0.80 & 1.61 & 0.76 \\
\hline Video & 1.62 & 0.89 & 1.84 & 0.97 & 1.65 & 0.94 \\
\hline Word document & 1.91 & 0.97 & 1.82 & 0.81 & 1.61 & 0.75 \\
\hline
\end{tabular}

Table 3. Students' perceptions of the importance, confidence and knowledge gained of resource.

When we compare educational videos to other resources, it was found that videos are the preferred choice of resources for students, followed by PowerPoint presentations, Word documents and, finally, podcasts (see Table 3). Examining the data for perceived preference, confidence and knowledge, it was found there were outliers, as assessed by inspection of each boxplot, therefore a Friedman test was used to determine if there were differences in the ratings in terms of perceived preference, confidence gained and knowledge gained. For each of these, pairwise comparisons were performed with a Bonferroni correction for multiple comparisons. Identical results were found for preference, confidence gained and knowledge gained. For preference, the resources were statistically significant $X^{2}(3)=43.918, p<0.001$. For confidence $X^{2}(3)=28.31, p<0.001$. For knowledge, $X^{2}(3)=32.438, p<0.001$. Again for each preference, confidence, and knowledge, post hoc analysis revealed exact same results. For preference, statistically significant differences were found for video $(\mathrm{Mdn}=1)$ compared to podcast $(\mathrm{Mdn}=3$ ) $(p<0.001)$, from PowerPoint $(M d n=2)$ to podcast $(p<0.001)$ and Word $(M d n=2)$ to podcast $(p<0.002)$. For perceived confidence, statistically significant differences were found for video ( $M d n=2)$ compared to podcast $(M d n=2)(p=0.001)$, from PowerPoint $(M d n=2)$ to podcast $(p=0.005)$ and Word $(M d n=2)$ to podcast $(p<0.008)$. Finally for perceived knowledge gained, statistically significant differences were also found for video $(M d n=1)$ compared to podcast $(M d n=2)(p<0.001)$, from PowerPoint $(M d n=1)$ to podcast $(p=0.001)$ and Word $(M d n=1)$ to podcast $(p=0.002)$. 
It has also been established that the vast majority of students at Northampton watch educational videos directly related to their course, and that educational videos are perceived to be the most important resource by students. Therefore establishing the key components of an educational video became the focus of the investigation. The results were clustered into three distinct groups, which have been labelled most important, midrange, and least important (see Table 4 below).

\begin{tabular}{|c|c|c|c|}
\hline & \multirow[t]{2}{*}{ Components } & \multicolumn{2}{|c|}{$\begin{array}{l}\text { How important are each of the following } \\
\text { components to you in educational videos } \\
\text { (1=very important, } 5 \text { = not very important) }\end{array}$} \\
\hline & & mean & std dev \\
\hline \multirow{4}{*}{ 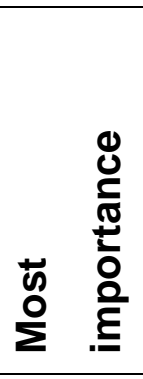 } & Content & 1.49 & 0.73 \\
\hline & Visual examples & 1.70 & 0.81 \\
\hline & $\begin{array}{l}\text { Recommendations from } \\
\text { lecturer }\end{array}$ & 1.89 & 0.77 \\
\hline & Production quality & 1.95 & 0.90 \\
\hline \multirow{5}{*}{ 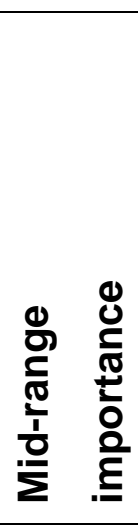 } & Quiz & 2.21 & 0.94 \\
\hline & $\begin{array}{l}\text { Seeing a presenter on } \\
\text { screen }\end{array}$ & 2.36 & 0.87 \\
\hline & $\begin{array}{l}\text { Produced by University of } \\
\text { Northampton staff }\end{array}$ & 2.38 & 0.86 \\
\hline & Animation & 2.41 & 0.94 \\
\hline & Humour & 2.41 & 1.08 \\
\hline \multirow{4}{*}{ 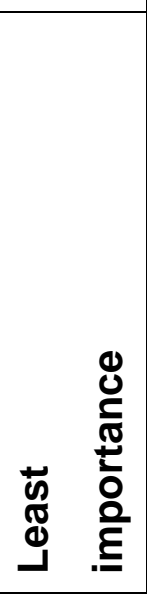 } & $\begin{array}{l}\text { Do not see a presenter } \\
\text { (voice over) }\end{array}$ & 2.56 & 0.85 \\
\hline & $\begin{array}{l}\text { Produced by an academic } \\
\text { not at the University of } \\
\text { Northampton }\end{array}$ & 2.74 & 0.62 \\
\hline & Music & 2.78 & 1.12 \\
\hline & $\begin{array}{l}\text { Produced by a non- } \\
\text { academic }\end{array}$ & 2.82 & 0.87 \\
\hline
\end{tabular}

Table 4. Importance to students of individual components of an educational video. 
Shapiro-Wilk tests were carried out to test the normality of each component of the data in respect of gender and year of study. On all occasions the results were significant, so the data had to be treated as non-parametric. Therefore, when looking for differences between the components, a Mann-Whitney test was carried out for gender and a Kruskal-Wallis test was carried out for level of study. In all instances, all results were not significant, thus there were no differences for any of the components by gender or level of study. Moreover, as opposed to looking at each component in isolation, each individual component was correlated (using Spearman's rank correlation) with the overall importance of educational videos (see Figure 1 below).

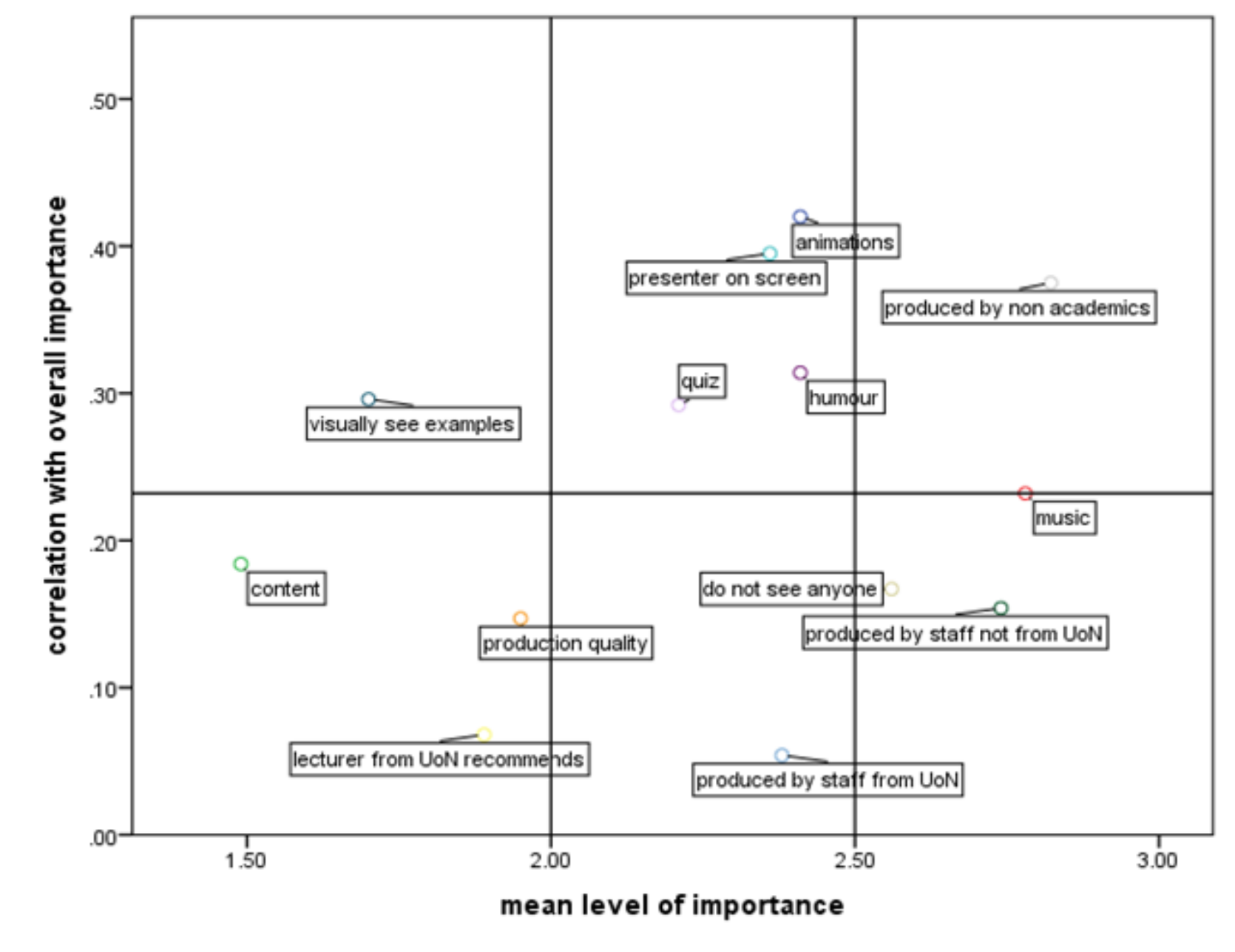

Figure 1. Individual components correlated with overall importance.

Here it can be seen that only one of the most important components, 'visually see examples', has a significant correlation with overall importance $(r=0.29, p<0.01)$. Therefore this component illustrates the key strength of an educational video. Individually it is perceived to be important by students, but it also demonstrates a significant correlation 
with overall importance. As for the remaining most important components (content $r=0.19$, $p>0.05$, production quality $r=0.14, p>0.05$, and lecturer from University of Northampton recommends $r=0.08, p>0.05)$, none significantly correlate with overall importance: therefore, although they are perceived to be individually important, that alone is not enough to make an educational video important to students. An interesting result was found when examining the mid-range components (animation $r=0.45, p<0.01$, presenter on screen $r=0.39, p<0.01$, humour $r=0.34, p<0.01$, and quiz $r=0.29, p<0.01)$. Although not individually important, they do correlate with overall importance and therefore, if attempted, should be completed to a high standard, as otherwise they risk having a negative impact on overall importance. This particular result will be expanded upon in the discussion section below.

The next objective under consideration was the optimum length of the video, and in particular whether they should be less than five minutes or not. Due to the fact that not all cells were represented sufficiently to carry out a chi-square test when looking for gender, a cross tabulation was produced which collapsed some of the options. A corresponding Fisher's Exact test was carried out (see Table 5). There was no significant difference between optimum time and gender, with both groups perceiving five minutes plus to be better ( $85.9 \%$ overall) than the alternative options $(p=0.35)$

\begin{tabular}{|l|l|l|l|}
\hline \multirow{2}{*}{} & \multicolumn{3}{|l|}{ What is the optimum time for an educational video? } \\
\cline { 2 - 4 } & $\begin{array}{l}\text { Less than 5 minutes } \\
\mathrm{n}(\% \text { gender })\end{array}$ & $\begin{array}{l}\text { 5 minutes plus } \\
\mathrm{n}(\% \text { gender })\end{array}$ & Total \\
\hline Male & $3(8.8 \%)$ & $31(91.2 \%)$ & 34 \\
\hline Female & $9(17.6 \%)$ & $42(82.4 \%)$ & 51 \\
\hline Total & $12(14.1 \%)$ & $73(85.9 \%)$ & 85 \\
\hline
\end{tabular}

Table 5. Cross tabulation of gender by optimum time.

For similar reasons, categories were collapsed for optimum time to less than five minutes and five minutes plus when looking at level of study. Furthermore, the level of study was collapsed into undergraduate and postgraduate. See Table 6 below for resulting cross tabulation. 


\begin{tabular}{|l|l|l|l|}
\hline \multirow{2}{*}{} & \multicolumn{3}{|l|}{$\begin{array}{l}\text { What is the optimum time for an educational } \\
\text { video? }\end{array}$} \\
\cline { 2 - 4 } & $\begin{array}{l}\text { Less than 5 minutes } \\
\mathrm{n}(\% \text { level) }\end{array}$ & $\begin{array}{l}5 \text { minutes } \\
\text { plus } \\
\mathrm{n}(\% \text { level })\end{array}$ & Total \\
\hline Undergraduate & $7(9.5 \%)$ & $67(90.5 \%)$ & 74 \\
\hline Postgraduate & $4(57.1 \%)$ & $3(42.9 \%)$ & 7 \\
\hline Total & $11(13.6 \%)$ & $70(86.4 \%)$ & 81 \\
\hline
\end{tabular}

Table 6. Cross tabulation of level of study by optimum time.

Here it can be seen that when Fisher's Exact Test is carried out the two-sided exact test is significant ( $p$ value $=0.006$ ). Thus it can be concluded there is a significant difference in the optimum time of a video for undergraduates and postgraduates, with undergraduates preferring greater than five minutes and postgraduates preferring under five minutes. This will impact on the design of educational videos when targeting a particular audience and is discussed in more detail in the next section.

\section{Qualitative}

From the focus group, five common themes emerged. They were, in no particular order: content; production; time; engagement; and added value. Each of these sections will now be explored. A selection of quotes will be used to represent each section. All quotes used are taken directly from the focus groups.

\section{Content}

It's all about content. If video is not delivering content I will find it in a book or somewhere else.

It was evident from the focus groups that content had to be the main contributor of an educational video. However, upon deeper analysis it was found that content on its own was not sufficient to make a good video. 


\section{Production}

The speaker was not looking towards the camera.

The background was quite distracting, I sort of drifted.

To be honest the first minute of him talking I would have closed it, it was the presenting style as well, he had his script in front of him, and it was not rehearsed well.

I think the animation was good but the way they were speaking, I don't think I could listen to that any longer than 2 minutes.

I find that when it's just someone talking on screen, I find it boring.

These comments have been grouped together and themed under the heading 'production'. However, this section also incorporates 'distraction', as there were elements of the production which caused immense distraction to the students. In particular they were noticing the backgrounds, accents, clothes and general appearance of the presenter in minute detail. Furthermore, a lot of attention and comments were made on how the message was put across and very few comments on the message itself.

\section{Time}

I was picking the videos based on their lengths, I don't think I would sit for the whole 16 minutes.

It says 'part one', so I wonder how many parts there are? (group laughs)

From the results witnessed in the questionnaire, it was interesting to note that overall, students perceived that videos of 5-10 minutes length were considered to be of the optimum length for an educational video. Moreover, videos of 10-30 minutes length were considered better than videos of less than 5 minutes. Students said that they would watch videos for 10 minutes or more, but when it came to reality, that was not always the case. 
Without complete motivation and engagement it was found that videos should definitely be no longer than 10 minutes.

\section{Engagement}

It is pointless of watching something if all I am doing is listening.

He was just reading slides which I could have done at home if I wanted to - I can read.

It didn't engage me.

The interactivity of video did work for me.

Again it was evident that unless a student is engaged in the video, it will be very difficult for them to learn effectively from the video. It was discovered that a video can be rich in content without being effective if the video did not also engage the student. The students considered that they needed to be actively involved to be fully engaged with the video and not just be a passive observer with no involvement. Moreover, the video had a negative impact if the student felt patronised, which was often the case if they were just being read to.

\section{Added value}

I will watch a video as I think it should be more beneficial to me...otherwise I will read a book (which is my preference).

If a lecturer recommended a video, I would watch it, but it would depend if it addressed which it needed to (same as book list). I would look, but it would have to be of benefit to me to keep watching all of it.

It showed you.

It is better going through examples. 
I would watch an educational video as long as I feel it is showing me something.

As with the results from the questionnaire, it was found that students wanted something extra from a video that they could not get from another resource. In particular, students wanted a practical example (i.e. to be shown something) which would have a more lasting impact on them than would be the case if they were simply told something.

The themes identified informed the simple model below which was derived from the focus groups (see Figure 2 below).

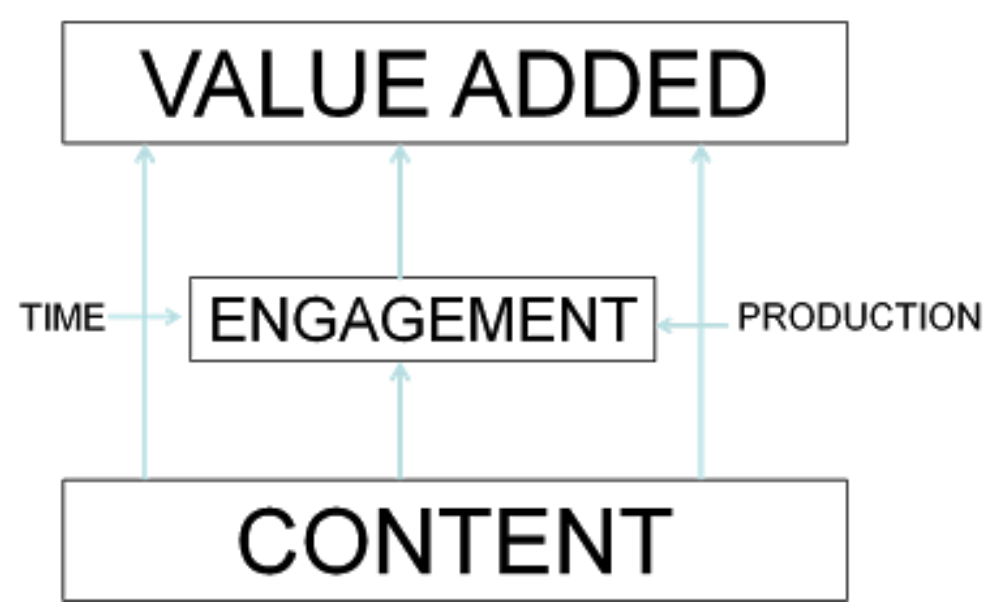

Figure 2. Model to demonstrate themes from focus groups.

At the base of the model, content has to be underlying. A video, however it engages students, must be fit for purpose and, ultimately, to provide students with the information they require. However, as already discovered, a video rich in content is not sufficient on its own. The goal of an educational video is to give the student something extra that they cannot get elsewhere or in another form. The video must provide added value, although it is not necessarily an easy step from content to added value. For that to happen a student must be engaged, and the time of the video and the production (and distractions) of the video will have an impact upon this. 


\section{Discussion and reflections}

These results have shown that students at Northampton overwhelmingly use educational videos for their studies. Therefore it is even more important that these resources are fit for purpose. Although not significant, the findings support the results of Tang and Austin (2009) by concluding videos are the preferred choice of resource for students. Educational videos engage students which leads to an increase in student motivation and, consequently, attention. Furthermore, Bliss et al. (2013) found that teachers also reported that students were more engaged and interested in educational videos. One possible reason for this is that students equated watching an educational video with watching a television programme, and that is why there is a higher interest and engagement, which leads to an increase in motivation. However, this is still unclear and needs to be investigated further, which was beyond the scope of this paper.

It was found in this study that the key strength, as perceived by students, of an educational video was the ability of the medium to provide visual examples. This result emphasised the work of Dale (1969, cited Atherton, 2013), who concluded that people generally remembered $50 \%$ of what they hear and see, compared to only $10 \%$ of what they read, and only $20 \%$ of what they hear. In addition, our results were consistent with many, but not all, of Mayer's (2009) multimedia principles. Although the principles were not specifically with video in mind, this research concurs with the following multimedia principles outlined by Mayer. In particular, the segmenting principle, as this allows for user paced segments; the signalling principle, which gives learners cues to highlight essential material; the multimedia principle, which argues people learn better from words and pictures than from words alone; the temporal principle, where corresponding words and pictures are presented simultaneously; the personalisation principle, where voices are delivered in a conversational style; finally the coherence principle, where extraneous information is excluded. One principle which this research disagreed with was the image principle which suggests learners do not necessarily learn better from seeing the presenter on screen as opposed to a voice over. This research is in favour of seeing the presenter on screen in preference of a voice over with the caveat that it is done well. All remaining principles were either not applicable to this research or there was no preference for or against.

In conclusion, students want something extra from a video that they cannot get from another resource. Although high quality content has to be underlying, content alone is not 
enough. Students need to be engaged and, in order for that to happen, time and production are influencing factors. While a student perceives they are benefiting from a video they will continue to watch. Therefore, when producing further videos at the UoN, it is recommended that videos will be segmented into organised clear steps. Key elements will be highlighted and audio and visual will be presented at the same time. When appropriate, visuals will be used to illustrate key points. The context of the video should be explained and the expectations of the learner should be managed and fulfilled. Finally, a conversational tone should be used to engage the listener and the length of the video should be kept to a minimum.

It is clear from the research that students at Northampton were found to have a positive attitude towards videos. Furthermore, the perceived importance of videos was higher than any other resource. Despite this result, perceived confidence and perceived knowledge gained from videos were not significantly different to PowerPoint or Word documents. However, it must be remembered this was dealing with students' perceptions, therefore it remains to be seen if the reality is any different. This goes beyond the scope of this study, hence further investigation is required to see if there are any correlations between perceptions and reality, and ultimately perceptions and learning achievement. Therefore, regardless of the medium adopted, materials need to be designed appropriately for the delivery method, and this is maybe more important than the medium it is delivered in. Tang and Austin (2009, p.1243) argue that:

It is not the technology, but the instructional implementation of the technology that contributes to learning effectiveness. It is important to investigate students' opinions regarding the technologies and the effective implementation of these technologies.

By investigating students' thoughts and perceptions, as this project has done, it can be seen that educational videos can be useful tools for students. Furthermore, having an open design process - supported by pedagogical theory, a working knowledge of Cognitive Load Theory and Cognitive Theory of Multimedia Learning, and input from students - can reduce the barriers for learners using educational videos. In turn, this can lead to a more learner-centred and decentralised approach, but before this can truly happen we must first ask the students what they want... what they really, really want. 


\section{Acknowledgement}

This research is an extension of the work undertaken as part of the undergraduate research bursaries at Northampton (URB@N) scheme. Special thanks to Nadach Musungu for her assistance in conducting and transcribing the focus group and to Rachel Maunder for making the URB@N grant available.

\section{References}

Atherton, J. (2013) Learning and teaching; enactive, iconic, and symbolic levels of representation [Online]. Available at:

http://www.learningandteaching.info/learning/dale-bruner.htm (Accessed: 18 July 2014).

Bates, T. (2011) OERs: the good, the bad and the ugly [Online]. Available at: http://www.tonybates.ca/2011/02/06/oers-the-good-the-bad-and-the-ugly/ (Accessed: 20 July 2014).

Bliss, T.J., Robinson, J., Hilton, J. and Wiley, D.A. (2013) 'An OER COUP: college teacher and student perceptions of open educational resources', Journal of Interactive Media in Education, 2013(4) [Online]. Available at: http://jime.open.ac.uk/article/view/252 (Accessed: 20 July 2014).

Clark, R.C. and Mayer, R. (2011) E-learning: and the science of instruction. $2^{\text {nd }}$ edn. London: John Wiley \& Sons.

Cooper, D. and Higgins, S. (2014) 'The effectiveness of online instructional videos in the acquisition and demonstration of cognitive, affective and psychomotor rehabilitation skills', British Journal of Education Technology, 46(4), pp. 768-779.

Creswell, J.W. (2009) Research design: qualitative, quantitative, and mixed method approaches. $3^{\text {rd }}$ edn. London: Sage. 
Hegarty, M., Kriz, S. and Cate, C. (2003) 'The roles of mental animations and external animations in understanding mechanical systems', Cognition and Instruction, 21(4), pp. 209-249.

Hilton III, J.L., Gaudet, D., Clark, P., Robinson, J. and Wiley, D. (2013) 'The adoption of open educational resources by one community college math department', The International Review of Research in Open and Distance Learning, 14(4) [Online]. Available at: http://www.irrodl.org/index.php/irrodl/article/view/1523/2652 (Accessed: 20 July 2014).

Ibrahim, M., Antonenko, P., Greenwood, C. and Wheeler, D. (2012) 'Effects of segmenting, signalling, and weeding on learning from educational video', Learning, Media and Technology, 37(3), pp. 220-235.

Ibrahim, M., Callaway, R. and Bell, D. (2014) 'Assessing the effect of instructional video design on students' learning outcome in an online technology integration course', Society for Information Technology \& Teacher Education International Conference. Jacksonville, Florida, USA 17-24 March, pp. 349-356.

Johnson, B. and Christian, L.B. (2008) Educational research: quantitative, qualitative, and mixed approaches. $3^{\text {rd }}$ edn. London: Sage.

Kannan, A. and Baker, S. (2014) Identifying presentation styles in online educational videos [Online]. Available at:

http://research.microsoft.com/pubs/231796/videoStyles.pdf (Accessed: 19 June 2015).

Kay, R. (2012) 'Exploring the use of video podcasts in education: a comprehensive review of the literature', Computers in Human Behavior, 28(3), pp. 820-831.

Kay, R. and Kletskin, I. (2012) 'Evaluating the use of problem-based video podcasts to teach mathematics in higher education', Computers \& Education, 59(2), pp. 619627. 
Littlejohn, A., Falconer, I. and McGill, L. (2008) 'Characterising effective eLearning resources', Computers \& Education, 50(3), pp. 757-771.

Lofland, J. and Lofland, L.H. (1995) Analyzing social settings: a guide to qualitative observation and analysis. Belmont: Wadsworth.

MacGillivray, H. and Croft, T. (2011) 'Understanding evaluation of learning support in mathematics and statistics', International Journal of Mathematical Education in Science and Technology, 42(2), pp. 189-212.

Mayer, R.E. (2009) Multimedia learning. New York: Cambridge University Press.

McGill, L., Falconer, I., Littlejohn, A. and Beetham, H. (2013) JISC/HE Academy OER Programme: Phase 3 Synthesis and Evaluation Report [Online]. Available at: https://oersynth.pbworks.com/w/page/59707964/ukoer3FinalSynthesisReport (Accessed: 21 June 2014).

McMillan, K. and Weyers, J. (2007) How to write dissertations and project reports. Pearson: Harlow.

Moreno, R. and Ortegano-Layne, L. (2008) 'Do classroom exemplars promote the application of principles in teacher education? A comparison of videos, animations, and narratives', Educational Technology and Research Development, 56(4), pp. 449-465.

Morrain, M. and Swarts, J. (2011) 'YouTutorial: a framework for assessing instructional online video', Technical Communication Quarterly, 21(1), pp. 6-24.

Nikoi, S.K., Rowlett, T., Armellini, A. and Witthaus, G. (2011) 'CORRE: a framework for evaluating and transforming teaching materials into open educational resources', Open Learning, 26(3), pp. 191-207.

Paas, F., Gog, T. and Sweller, J. (2010) 'Cognitive Load Theory: new conceptualizations, specifications, and integrated research perspectives', Educational Psychology Review, 22(2), pp. 115-121. 
Panke, S. and Seufert, T. (2013) 'What's educational about open educational resources? Different theoretical lenses for conceptualising learning with OER', E-Learning and Digital Media, 10(2), pp. 116-134.

Tang, T.L.P. and Austin, M.J. (2009) 'Students' perceptions of teaching technologies, application of technologies, and academic performance', Computers \& Education, 53(4), pp. 1241-1255.

Vieira, I., Lopes, A. and Soares, F. (2014) The potential benefits of using videos in higher education [Online]. Available at: http://recipp.ipp.pt/handle/10400.22/4853 (Accessed: 19 August 2015).

Wiley, D. (2010) 'Openness as Catalyst for an Educational Reformation', Educause Review, 45(4), pp. 14-20.

Williams, K., Kear, K., Rosewell, J. and Fereira, G. (2011) 'Incorporating quality assurance criteria for OER and Social Networking in the E-xcellence QA methodology', 24th ICDE World Conference, 'Expanding Horizons' - New approaches to Open and Distance Learning. Bali, Indonesia 2-5 October [Online]. Available at: http://oro.open.ac.uk/30392/1/KW ICDE Sub pdf.pdf (Accessed: 20 July 2014).

YouTube (2015) YouTube press statistics [Online]. Available at: https://www.youtube.com/yt/press/ (Accessed: 19 August 2015).

\section{Author details}

Paul Rice is an Academic Practice Tutor at the University of Northampton. He has been in this job role for six years and oversees the mathematics and statistics provision and support.

Robert Farmer works as a Learning Designer and as an Academic Practice Tutor at the University of Northampton. 